\title{
Persistent Newcastle disease virus infection in bladder cancer cells is associated with putative pro-survival and anti-viral transcriptomic changes
}

Lee-Chin Chan ${ }^{1,2}$, Jeevanathan Kalyanasundram ${ }^{1}$, Sze-Wei Leong ${ }^{1}$, Mas Jaffri Masarudin ${ }^{3,4}$, Abhi Veerakumarasivam ${ }^{2,5,6}$, Khatijah Yusoff ${ }^{1,2,4}$, Soon-Choy Chan ${ }^{2,7^{*}}$ and Suet-Lin Chia ${ }^{1,4^{*}}$

\begin{abstract}
Background: Newcastle disease virus (NDV) is an oncolytic virus with excellent selectivity against cancer cells, both in vitro and in vivo. Unfortunately, prolonged in vitro NDV infection results in the development of persistent infection in the cancer cells which are then able to resist NDV-mediated oncolysis. However, the mechanism of persistency of infection remains poorly understood.

Methods: In this study, we established persistently NDV-infected EJ28 bladder cancer cells, designated as EJ28P. Global transcriptomic analysis was subsequently carried out by microarray analysis. Differentially expressed genes (DEGs) between EJ28 and EJ28P cells identified by the edgeR program were further analysed by Gene Set Enrichment Analysis (GSEA) and Ingenuity Pathway Analysis (IPA) analyses. In addition, the microarray data were validated by RT-qPCR.

Results: Persistently NDV-infected EJ28 bladder cancer cells were successfully established and confirmed by flow cytometry. Microarray analysis identified a total of 368 genes as differentially expressed in EJ28P cells when compared to the non-infected EJ28 cells. GSEA revealed that the Wnt/ $\beta$-catenin and KRAS signalling pathways were upregulated while the TGF- $\beta$ signalling pathway was downregulated. Findings from this study suggest that the upregulation of genes that are associated with cell growth, pro-survival, and anti-apoptosis may explain the survivability of EJ28P cells and the development of persistent infection of NDV.

Conclusions: This study provides insights into the transcriptomic changes that occur and the specific signalling pathways that are potentially involved in the development and maintenance of NDV persistency of infection in bladder cancer cells. These findings warrant further investigation and is crucial towards the development of effective NDV oncolytic therapy against cancer.
\end{abstract}

\footnotetext{
* Correspondence: chansoonchoy@perdanauniversity.edu.my;

suetlin@upm.edu.my

${ }^{2}$ Malaysia Genome Institute, Ministry of Science, Technology and Innovation,

Jalan Bangi, 43000 Kajang, Selangor Darul Ehsan, Malaysia

${ }^{1}$ Department of Microbiology, Faculty of Biotechnology and Biomolecular

Sciences, Universiti Putra Malaysia, UPM, 43400 Serdang, Selangor Darul

Ehsan, Malaysia

Full list of author information is available at the end of the article
}

(c) The Author(s). 2021 Open Access This article is licensed under a Creative Commons Attribution 4.0 International License, which permits use, sharing, adaptation, distribution and reproduction in any medium or format, as long as you give appropriate credit to the original author(s) and the source, provide a link to the Creative Commons licence, and indicate if changes were made. The images or other third party material in this article are included in the article's Creative Commons licence, unless indicated otherwise in a credit line to the material. If material is not included in the article's Creative Commons licence and your intended use is not permitted by statutory regulation or exceeds the permitted use, you will need to obtain permission directly from the copyright holder. To view a copy of this licence, visit http://creativecommons.org/licenses/by/4.0/ The Creative Commons Public Domain Dedication waiver (http://creativecommons.org/publicdomain/zero/1.0/) applies to the data made available in this article, unless otherwise stated in a credit line to the data. 
Keywords: Newcastle disease virus, Bladder Cancer, Persistent infection, Transcriptome analysis, GSEA, Wnt/ $\beta$ catenin signalling

\section{Background}

Newcastle disease virus (NDV) is a negative, nonsegmented, single-stranded RNA paramyxovirus. Despite being pathogenic against the avian species, NDV only causes pharyngitis, conjunctivitis and mild flu-like symptoms in humans [1]. NDV has been studied extensively in vitro and in vivo for its oncolytic properties against various types of cancers [2-5]. The virus has been shown to selectively target cancer cells while leaving normal cells unharmed $[5,6]$. It was postulated that the selectivity of NDV is due to defects in antiviral responses that favour viral replication such as the production of interferons by cancer cells $[7,8]$. While NDV mediates oncolysis through the activation of intrinsic and extrinsic apoptosis pathways [9], it can also trigger a long-term adaptive immune response against infected cancer cells [10].

However, persistent infection of NDV has been reported in colorectal cancer cells [11]. Interestingly, the persistently infected colorectal cancer cells were found to harbour viral progenies that produced smaller plaques as compared to the uninfected cancer cells [11]. In a separate study, mutations in the $\mathrm{HN}$ and $\mathrm{F}$ genes were found in the viral progenies that were isolated from persistently infected ovarian cancer cells, linking hyperfusogenic NDV activity and the development of persistent infection [12]. Pertinently, the persistently infected cancer cells were resistant to NDV-mediated oncolysis [12]. Thus, the successful translation of NDV as an oncolytic viral therapeutic in clinic is dependent on the ability to overcome the potential risk of persistent infection.

Interestingly, not all cancer cells develop persistent infection of NDV [11]. Intrinsic cellular factors are thought to play a crucial role, but they remain poorly understood. In this study, we aimed to identify genes that are associated with persistent infection of NDV in EJ28 bladder cancer cells. By comparing the transcriptomic profiles of persistently infected EJ 28 cells and uninfected EJ28 cells, we identified differentially expressed genes (DEGs) and pathways that provide novel insights towards our improved understanding of persistent infection of NDV in bladder cancer cells.

\section{Methods}

\section{Viruses}

The method of NDV propagation was previously described [11, 13]. Briefly, the velogenic strain AF2240 was propagated in 9 day-old embryonated eggs and further purified by using a sucrose gradient of $20 \%(\mathrm{w} / \mathrm{v})$ to $60 \%$ $(w / v)$. NDV stock was quantified using plaque assays as previously described [13]. Briefly, $2 \times 10^{6}$ of SW620 colorectal cancer $(\mathrm{CRC})$ cells were seeded into each well of a 6-well plate and incubated in $5 \% \mathrm{CO}_{2}$ at $37^{\circ} \mathrm{C}$. Cells were incubated for $48 \mathrm{~h}$ to ensure it reached $100 \%$ confluence before a plaque assay was performed. The recombinant NDV harbouring the GFP gene, rAF-GFP was generated using reverse genetics. The GFP gene was amplified and inserted into the $\mathrm{M} / \mathrm{F}$ non-coding region of a full-length cDNA clone of the NDV strain AF2240. The recombinant virus was recovered in BSR T7/5 baby hamster kidney cells stably expressing T7 RNA polymerase and subsequently propagated in 10-day old embryonated eggs. Sequencing of the viral genome confirmed the presence of the GFP gene.

\section{Establishment of persistently infected EJ28 cells model}

Persistent infection of NDV in cancer cells was performed as described by Chia et al. [11]. Briefly, EJ28 bladder cancer cells $\left(1 \times 10^{6}\right.$ cells $)$ were seeded into each well of a 6-well plate. On the following day, the confluent monolayer of cancer cells was washed with $1 \times$ PBS followed by infection with NDV at a multiplicity of infection (MOI) of 1 . The plate was incubated for an hour and rocked at every $15 \mathrm{~min}$ interval. The cells were then rinsed with $1 \times \mathrm{PBS}$, replenished with fresh maintenance media (MM; DMEM supplemented with $2 \%$ foetal bovine serum, FBS) and finally incubated for $96 \mathrm{~h}$ in $5 \%$ $\mathrm{CO}_{2}$ at $37^{\circ} \mathrm{C}$. Micrographs of the infected cells were taken regularly to record the progression. The surviving cancer cells were then rinsed with $1 \times \mathrm{PBS}$ and fresh growth medium (GM; DMEM supplemented with $10 \%$ FBS) was added to allow the surviving cells to grow. Once the cells grew to confluency, the cells were reinfected again with NDV as described above. This process was repeated for another two times to select for truly persistently infected cancer cells. These persistently infected cells were then designated as EJ28P.

\section{Annexin V/Propidium iodide assay}

Reinfection of the persistently infected EJ28P with rAFGFP was carried out as described above. The cells were passaged continuously. Several passages $(1,15,20$ and 25) were selected to determine the presence of NDV in the EJ28P-GFP cells. The cells were trypsinised by using $0.25 \%(\mathrm{w} / \mathrm{v}$ ) of trypsin-EDTA (Gibco, USA), mixed with $1 \times \mathrm{PBS}$ at equal volume and then centrifuged at 1000 rpm (Centrifuge 5424, Eppendoff, Germany). The resulting cell pellet was stained with Alexa Fluor 647 Annexin 
$\mathrm{V}$ apoptosis detection kit (BioLegend, USA) according to the manufacturer's protocol. The stained cells were then subjected to flow cytometric analysis (Novocyte, Acea Biosciences, USA). By using the NovoExpress Software, 10,000 single cells were gated, and a graph plotted with the FITC channel set as the X-axis and cell count set as the Y-axis. Uninfected EJ28P cells were used as the negative control.

\section{RNA extraction and microarray analysis}

Total RNA of EJ28 and EJ28P cells were extracted using RNeasy MinElute ${ }^{\text {Tu }}$ Kit (Qiagen, The Netherlands) according to the manufacturer's protocol. The RNA quantity and purity were analysed by NanoPhotometer (Implen, Germany). RNA samples with A260/A280 ratio of 2.0 and above were subjected to Bioanalyzer (2100 Expert, Agilent Technologies, USA) analysis to determine the integrity of the extracted RNA. Only RNA samples with an RNA integrity number (RIN) of 8 and above were selected for the subsequent analyses. RNA samples with RIN values lower than 8 were re-purified with the RNeasy MinElute ${ }^{\mathrm{Tm}}$ Kit (Qiagen, The Netherlands) according to the manufacturer's protocol. The RNA samples were then diluted to $300 \mathrm{ng} / \mu \mathrm{L}$ and subsequently labelled using TargetAmp ${ }^{\text {TM }}$-Nano Labeling Kit for Illumina ${ }^{\circ}$ Expression BeadChip ${ }^{\circ}$ (Epicentre, USA). All incubation steps were performed on the Veriti 96-Well Thermal Cycler (Applied Biosystems, USA). Subsequently, the generated biotin-aRNA was purified using the RNeasy MinElute Cleanup Kit (Qiagen, Germany) according to the manufacturer's protocol. The purified biotin-aRNA was quantified and further diluted to a concentration of $150 \mathrm{ng} / \mu \mathrm{L}$ in a $15 \mu \mathrm{L}$ solution, followed by analysing it on the Bioanalyzer using the RNA Nano Chip. The RNA samples that passed the QC were run on the HumanHT-12 v4 Expression BeadChip (Illumina, USA). The BeadChip was hybridised for $18 \mathrm{~h} 24 \mathrm{~min}$ at $58^{\circ} \mathrm{C}$, and the detection was carried out using Cy3Streptavidin (Invitrogen, USA). The hybridised BeadChip microarray was scanned using the iScan System (Illumina, USA). The microarray data were submitted to the GEO database and the accession number is GSE163881.

\section{Differentially expressed genes (DEG) and gene set enrichment analysis (GSEA)}

DEGs between EJ28P and EJ28 obtained from the iScan System was presented as a Volcano plot. The plot was constructed by plotting the $-\log 10$ of the $p$-values on the $\mathrm{Y}$-axis and $\log 2$ fold change on the $\mathrm{X}$-axis. Subsequently, the edgeR program was used to select genes that had significant changes $(P a d j<1 e-10)$ with an absolute $\log 2$ fold change of 2 (upregulated genes) and -2 (downregulated genes). GSEA was performed to identify relevant biological significances by using the latest version of GSEA software (4.1.0) downloaded from Broad Institute Gene Set Enrichment Analysis website (www.broad.mit.edu/gsea). The enrichment gene sets used were selected from MSigDB, namely, hallmark $(\mathrm{H})$, curated (C2), oncogenic (C6) and immunologic (C7) gene sets. The phenotype label was persistent infection versus control and the number of permutations was set to 1000. Significance of enrichment magnitude was set at a False Discovery Rate (FDR) of $25 \%$ for GSEA.

\section{Ingenuity pathway analysis (IPA)}

DEGs with $\log 2$ fold change of $>2$ (upregulated genes) and $<2$ (downregulated genes) were selected and analysed using IPA (QIAGEN Inc., https://www. qiagenbioinformatics.com/products/ingenuity-pathwayanalysis). The software uses a network generation algorithm to segment the network map between molecules into multiple networks. In addition, IPA was also used to compare the relationship among these DEGs to identify key regulators within the network.

\section{RT-qPCR analysis}

The total RNA extracted from EJ28 and EJ28P was converted into cDNA using SensiFAST ${ }^{\mathrm{Tm}}$ cDNA synthesis kit according to the manufacturer's protocol (Bioline, United Kingdom). Quantitative reverse transcription PCR (RT-qPCR) analysis was performed in three technical replicates to measure the relative gene expression of five randomly selected DEGs from the microarray dataset. The delta-delta $\mathrm{Ct}$ method was used to determine the expression ratio between EJ28P and EJ28 cells, where normalisation was performed using three housekeeping genes, namely, TBP (QT00000721), SDHA (QT00059486), and GAPDH (QT00079247). The five selected DEGs were BNIP3 (QT00024178), S100A4 (QT00014259), DDIAS (QT02451288), CASP9 (QT00036267), and $A P O B E C 3 B$ (QT00040733). All the primers used in this study were purchased from Qiagen (QuantiTect@ Primer Assay).

\section{Results}

Establishment of NDV-persistently infected EJ28 (EJ28P) cells

When the EJ28 bladder cancer cells were first infected with the NDV strain AF2240 (MOI of 1), majority of the infected cells died. The surviving subpopulation of cells persisted in a state of slow growth for about two weeks (Fig. 1). Once the surviving subpopulation reached confluency on day 17, the cells were reinfected with NDV (MOI of 1 ) and subsequently reinfected again on day 21 . No gross cytopathic effects were observed upon NDV reinfection. The surviving cells from the first NDV infection appeared to be resistant to NDV-mediated oncolysis. However, these cells could either have been a result 

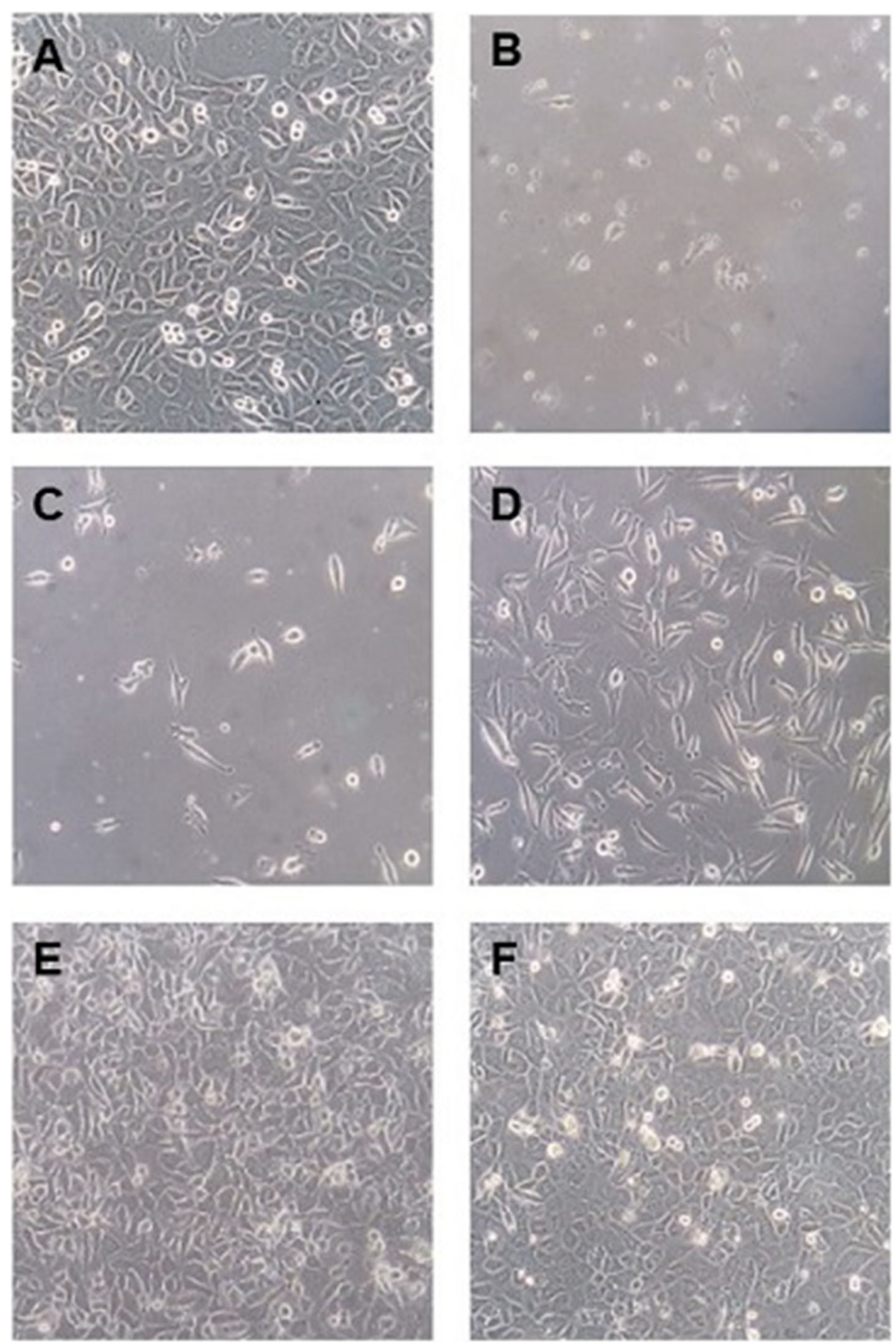

Fig. 1 Establishment of NDV-persistently infected EJ28P cells. EJ28P cells were established after three NDV infections at MOI of 1. A subpopulation of cells that survived the first infection were allowed to grow to confluency and were reinfected twice with NDV. (A) Day 1 (first infection), (B) Day 5, (C) Day 12, (D) Day 17 (second infection), (E) Day 21 (third infection) and (F) Day 27

of the preferential selection of inherently resistant subpopulation of cells during the first infection or the acquiring of persistency of infection in culture post-infection; or a combination of both. These persistently NDV-infected cells were designated as EJ28P.

\section{EJ28P cells harbour NDV over multiple passages and are resistant towards NDV-mediated oncolysis}

In order to compare the NDV cytotoxicity against EJ28P and EJ28 cells, both cells were infected with NDV $(\mathrm{MOI}=1)$ and observed under the microscope at 120 hpi. As previously observed during the establishment of 
EJ28P, the EJ28 cells experienced cytopathic effects with only a few surviving cells. The EJ28P, on the other hand, did not display any gross NDV-induced cytopathic effects (Fig. 2a). The viable cells post-NDV infection was qualitatively determined by neutral red staining (Fig. 2b). The wells containing EJ28 cells infected with NDV appeared transparent with only a few adherent cells stained with neutral red whereas the well containing EJ28P cells infected with NDV appeared to be completely stained in red; much like the wells containing the mock-infected cells. The virus titre in these EJ28P cells were determined via plaque assay (Fig. 2c). The EJ28P were found to produce viral progenies up to $2.2 \times 10^{7} \mathrm{PFU} /$ $\mathrm{mL}$ comparable to that of the infected EJ28. Interestingly, the plaques produced by NDV in EJ28P cells were smaller in size as compared to that produced by NDV during the 1st infection of EJ28 cells. (see Additional file 1: Fig. S1).

The cell viability of mock- and NDV-infected EJ28 and EJ28P cells from 0 hpi to 120 hpi was also analysed using trypan blue exclusion test (Fig. 2d). At $24 \mathrm{hpi}$, the relative cell viabilities were similar across all four cells.
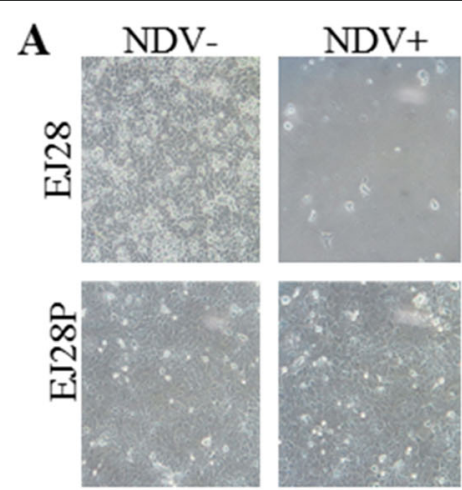

C

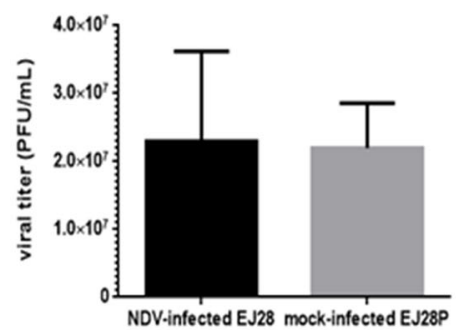

$\mathbf{E}$

E

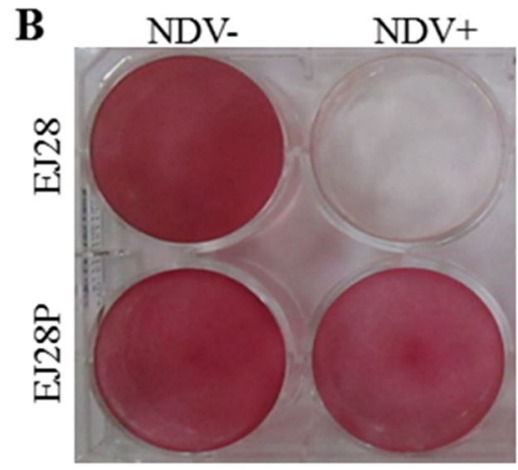

D $600.0 \sim$ EJ28 mock

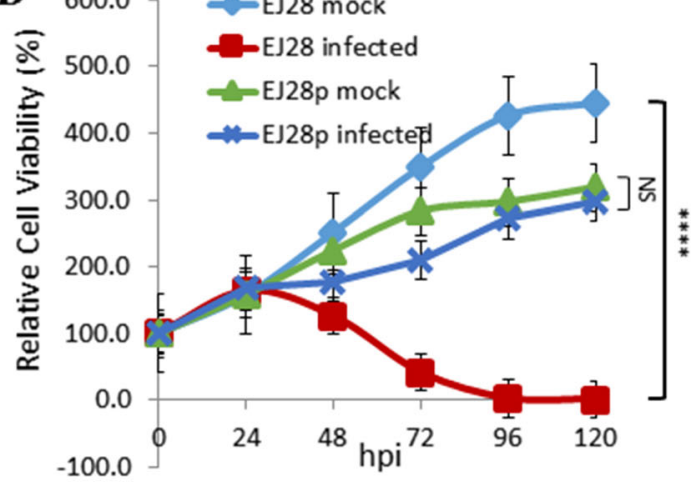

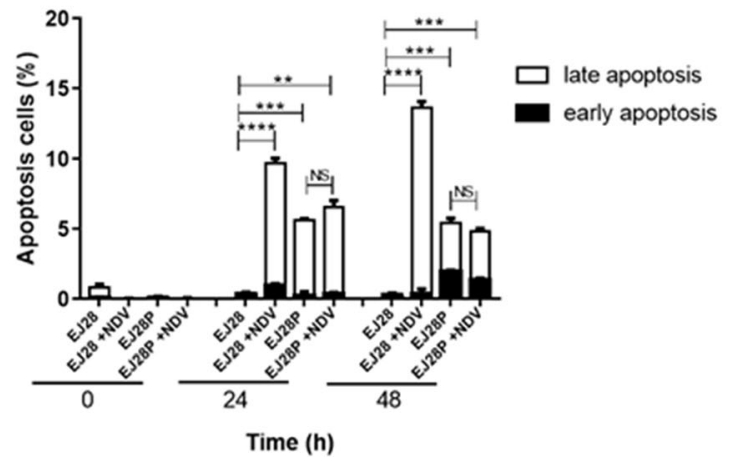

Fig. 2 Confirmation of NDV persistently infected EJ28P cells. (A) Microscopic image and (B) neutral red staining of mock- and NDV-infected EJ28P and EJ28 cells (MOI of 1) at 120 hpi. (C) Virus titre of the culture supernatant collected from EJ28P and NDV-infected EJ28 (positive control) cells. (D) Relative viability of mock- and NDV-infected EJ28P and EJ28 cells (MOI =1) from 0 hpi to120 hpi. (E) Apoptosis analysis of NDV-infected and mock-infected EJ28 and EJ28P cells stained with Annexin V and propidium iodide, followed by flow cytometric analysis. Percentage of early and late apoptotic cells are presented in a bar graph. All data were presented as mean of biological triplicate readings. Value with ${ }^{* * *},{ }^{* *},{ }^{* *}$, and NS indicate a $P$ value of $<0.0001,<0.001,<0.01$, and not significant, respectively 
However, significant differences in relative cell viability values were observed in the subsequent time points. At $120 \mathrm{hpi}$, there were less than $1 \%$ viable NDV-infected EJ28 cells. In contrast, the mockinfected EJ28 cells had quadrupled while the mockand NDV-infected EJ28P cells had tripled in that same 5-day period. Although the relative cell viability was lower than that of the parental cells, EJ28P cells appear to be resistant towards NDV-mediated oncolysis. To further confirm the presence of NDV in EJ28P, we reinfected these cells using a recombinant NDV strain AF2240 that harbours the green fluorescent protein (GFP) gene (rAF-GFP) at MOI of 1 . Subsequent observation under a fluorescence microscope showed that GFP was expressed in the EJ28P cells (see Additional file 1: Fig. S2). The GFP signal was detectable in the EJ28P cells even after 25 passages. These findings suggest that persistently infected EJ28P cells are susceptible to NDV infection and was able to continuously produce viral proteins through multiple cell passages.
Annexin V/Propidium Iodide assay was also conducted on the mock- and NDV-infected EJ28 and EJ28P cells and analysed by flow cytometry (see Additional file 1 : Fig. S3). At both time points ( $24 \mathrm{hpi}$ and $48 \mathrm{hpi}$ ), there were no statistically significant differences in the percentages of apoptotic cells (late or early) between mockand NDV-infected EJ28P cells. This further validates that NDV reinfection has limited oncolytic effect on persistently infected cells (Fig. 2e). Nevertheless, it is interesting to note that although no gross cytopathic activity was observed in the earlier assays, there were a relatively small percentage $(\sim 5 \%)$ of apoptotic cells in both mockand NDV-infected EJ28P cells. Similarly, apoptotic cells were detected in persistently infected Hep2 cells in a previous study [14].

\section{A panel of $\mathbf{2 0}$ gene expression signatures provides accurate discriminatory power to distinguish NDV- persistently infected cells from their parental cells} Microarray analysis of the global gene expression identified a total of 368 genes that were significantly

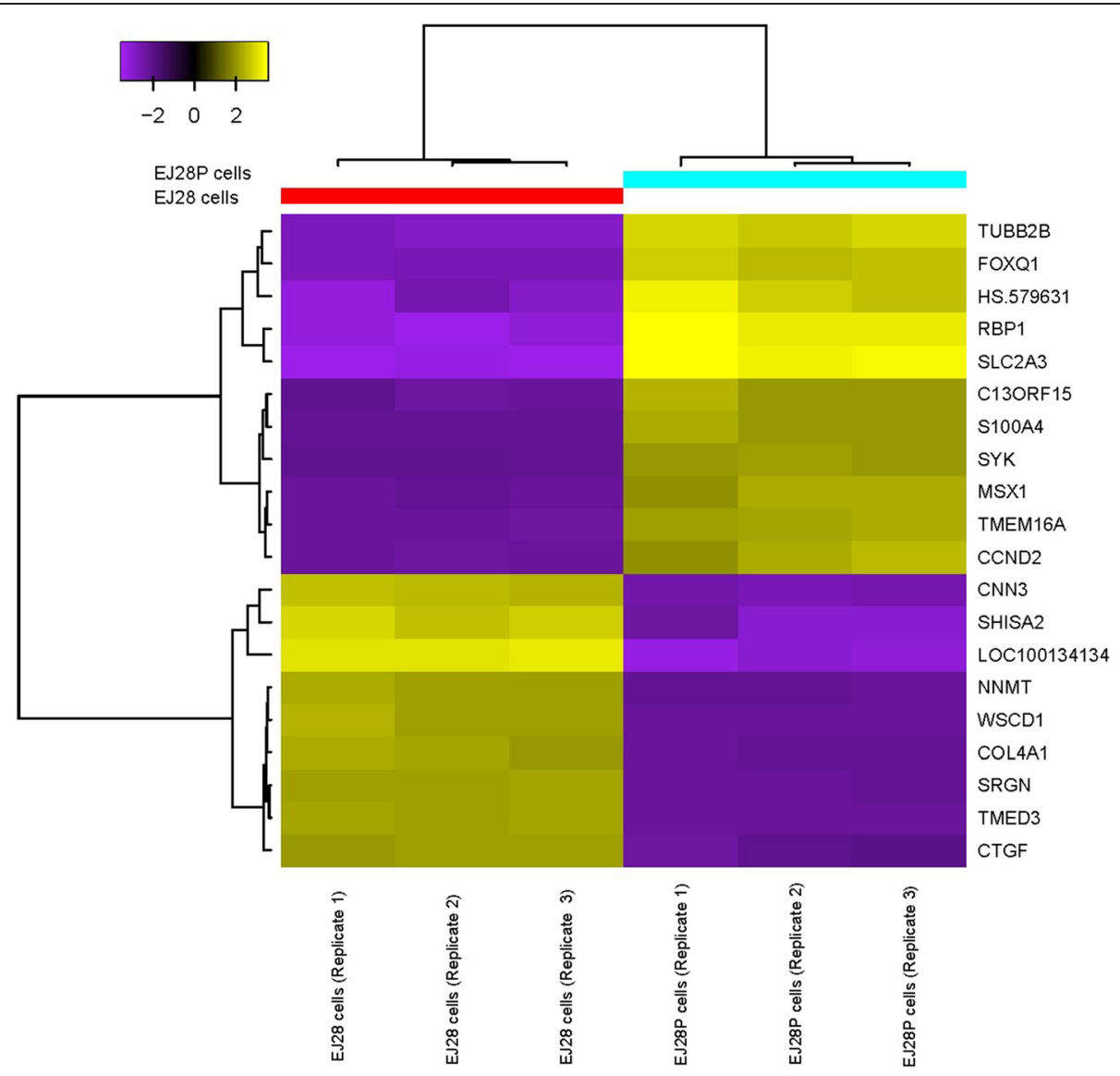

Fig. 3 Heatmap of differential gene expression between EJ28 and EJ28P cells. The gene expression profiles of 20 genes provided sufficient discriminatory power to accurately separate EJ28 and EJ28P cells into 2 distinct clusters representing bladder cancer cells and persistently infected bladder cancer cells. Downregulated genes are represented in purple (expression value $<0$ ) while upregulated genes are represented in yellow (expression value $>0$ ) 
differentially expressed in EJ28P cells as compared to EJ28 cells. Of these, 229 genes were upregulated and 139 genes were downregulated in EJ28P cells (see Additional file 2: Table S1). A heatmap (Fig. 3) was generated using 20 DEGs, which provided sufficient discriminatory power to separate both EJ28 and EJ28P cells into two distinct hierarchical clusters, which are the bladder cancer cells and the persistently infected bladder cancer cells clusters, respectively. Although GSEA identified more than 20 genes that were distinctively expressed between these two clusters of cells (see Additional file 3: Fig. S4), only 20 genes were needed to establish a panel of genes to distinguish persistently infected EJ28P cells from non-infected EJ28 cells.

It was found that regulators of cell cycle and cell proliferation such as S100A4 [15, 16], CCND2 [17], C13ORF15 (RGCC) [18, 19], and SYK [20, 21] and genes associated with glucose or ion transport such as $S L C 2 A 3$ [22-24] and TMEM16A (ANO1) [25, 26] were upregulated in the persistently infected bladder cancer cells. While CNN3, SHISA2, TMED3, SRGN were downregulated in persistently infected bladder cancer cells. It is worth mentioning that SHISA2 is a negative regulator of Wnt/ $\beta$-catenin signalling pathway [27-29] while $S R G N$ is a mediator of granule-mediated apoptosis [30-32]. The details of these 20 significant DEGs are shown in Additional file 3: Table S2.

\section{GSEA identifies pathways associated with cell survival, cell growth and differentiation as upregulated in EJ28P} The microarray data analysis with GSEA based on MSigDB hallmark gene sets revealed the most enriched pathways in EJ28P cells Fig. 4 (4A and 4B). Among these pathways, Wnt/ $\beta$-catenin signalling pathway (Fig. 4c) was the most induced gene set in the hallmark with an NES of 1.31. Figure $4 \mathrm{~d}$ shows the list of genes associated with the canonical Wnt/ $\beta$-catenin signalling pathway such as CCND2, AXIN2, LEF1, NKD1, and NOTCH1 that were found to be upregulated in EJ28P. Meanwhile, some downregulated DEGs were found to be enriched in the TGF- $\beta$ signalling pathway (Fig. 4e \& f). GSEA showed that KRAS signalling was also enriched in EJ28P cells (see details in Additional file 3: Table S3). DEGs that are involved in the inhibition of apoptosis such as TNFRSF1B, TMEM158, and FGF9 were found to be enriched in this pathway, [33-37].

IPA was employed to search for potential interactions between the DEGs that were identified from the microarray data. Corresponding to the GSEA findings, one of the identified networks (Fig. 5) revealed several key genes associated with the $\mathrm{Wnt} / \beta$-catenin signalling pathway such as CDH1, EPAS1, AXIN2, LEF1, NKD1. The network showed that EPAS1 was an important regulator gene that controls multiple genes while $C D H 1$ has multiple interactions with other genes.

Subsequently, GSEA was performed using curated (Fig. 6a), immunologic (Fig. 6b), and oncogenic (Fig. 6c) gene sets collection. The curated gene sets revealed that the top 3 significantly enriched pathways were GPCRs class B Secretin-like $(\mathrm{NES}=1.97$; FDR $=0.186)$, metabolism of amine-derived hormones $(\mathrm{NES}=1.92$; $\mathrm{FDR}=$ $0.155)$ and benign skin tumour $(\mathrm{NES}=1.90 ; \mathrm{FDR}=$ $0.123)$. GSEA analysis of 189 oncogenic gene sets identified the signature characteristics of genes downregulated in HEK293 cells upon knockdown of ATM (NES = 1.67; FDR $=0.062)$, genes upregulated in MCF10A cells (breast cancer) upon knockdown of BRCA1 (NES = 1.66; FDR $=0.062$ ); and genes downregulated in epithelial cells expressing the mutated form of KRAS ( $\mathrm{NES}=1.64$; $F D R=0.062)$ to be the top 3 significantly enriched in EJ28P cells. The immunologic gene sets revealed the top 3 significantly enriched immune-related gene sets were for the signature characteristics of genes upregulated in response to trivalent inactivated influenza (TIV) vaccination (NES $=1.73$; FDR $=0.055$ ); genes downregulated in HEK293 cells at $2 \mathrm{~h}$ after stimulation by muramyl dipeptide $(\mathrm{NES}=1.71$; $\mathrm{FDR}=0.090)$; genes upregulated in regulatory $\mathrm{T}$ cells due to altered function of FOXP3 $(\mathrm{NES}=1.71 ; \mathrm{FDR}=0.078)$.

\section{Validation of microarray data by RT-qPCR}

In order to validate the microarray results, five DEGs were randomly selected and subjected to RT-qPCR analysis. Based on the similar expression patterns, the $\log _{2}$ fold change values derived from the RT-qPCR data validated the DEGs that were identified from the microarray-based profiling exercise. (Fig. 7).

\section{Discussion}

Despite NDV's ability to lyse cancer cells, some cancer cells including colorectal cancer and ovarian cancer are able to resist viral-mediated oncolysis and eventually become persistently infected with NDV. The intrinsic mechanism underlying persistent infection of NDV remains elusive. In this study, we established persistently NDV-infected bladder cancer cells, EJ28P, by challenging EJ28 bladder cancer cells with NDV infection over a period of 2 weeks. Eventually, there was a subpopulation of cells that survived the viral infection and grew uninterruptedly despite exposure to a second and third infection. These findings are similar to that reported in a study involving colorectal cancer cells [11].. These cells were verified to be persistently infected by analysing the cell viability, plaque assay of spent medium, and Annexin V/Propidium Iodide assay. The overall characteristics of EJ28P were similar to other NDV persistently infected cancer cells that have been reported previously 


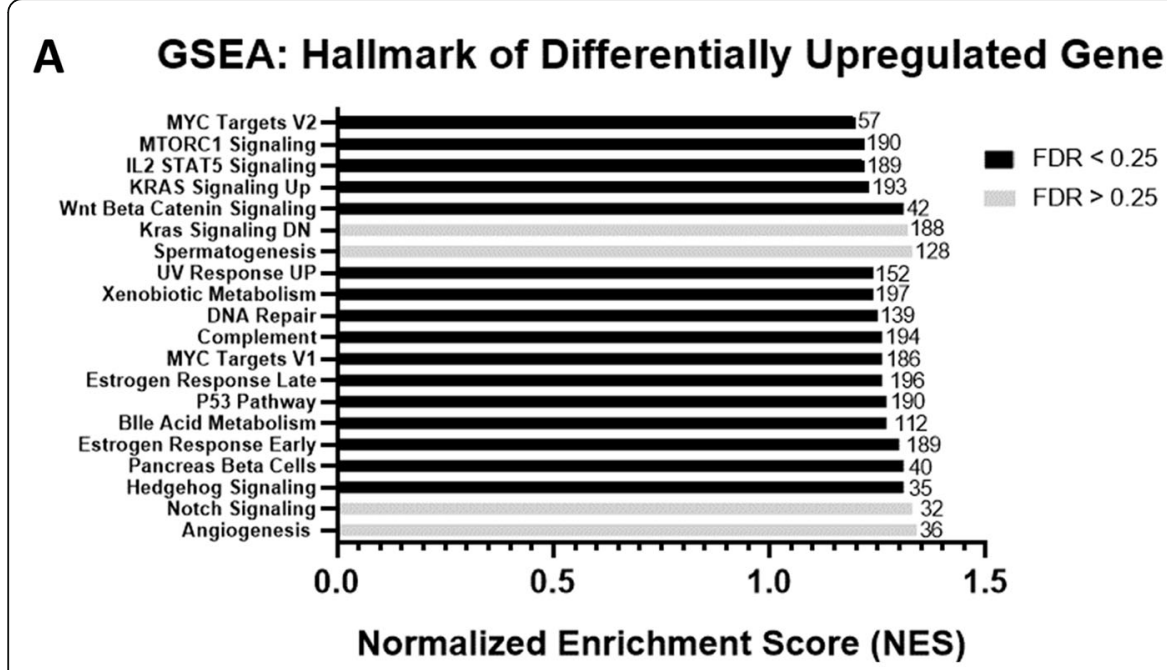

\section{B GSEA: Hallmark of Differentially Downregulated Gene}

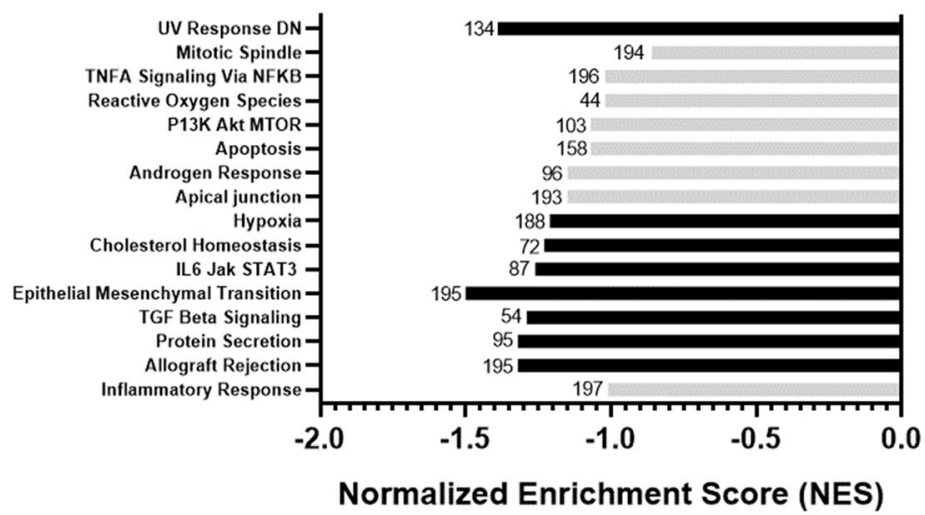

- $\mathrm{FDR}<0.25$

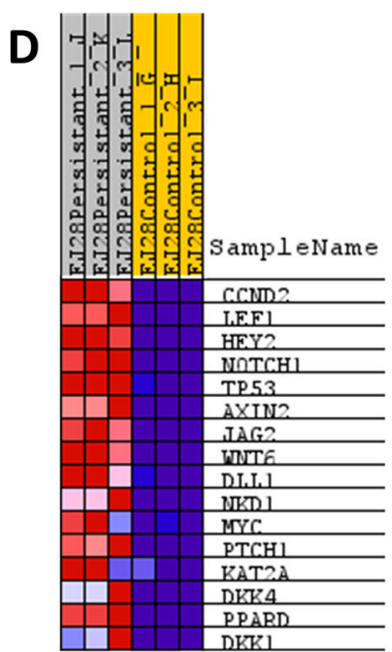

$\mathbf{F}$

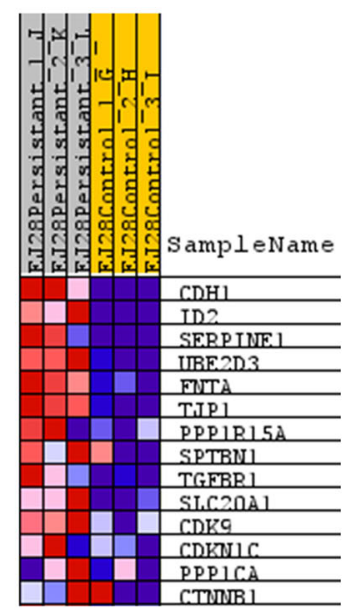

C

Enrichment plot:

C HALLMARK_WNT_BETA_CATENIN_SIGNALING

FDR $>0.25$
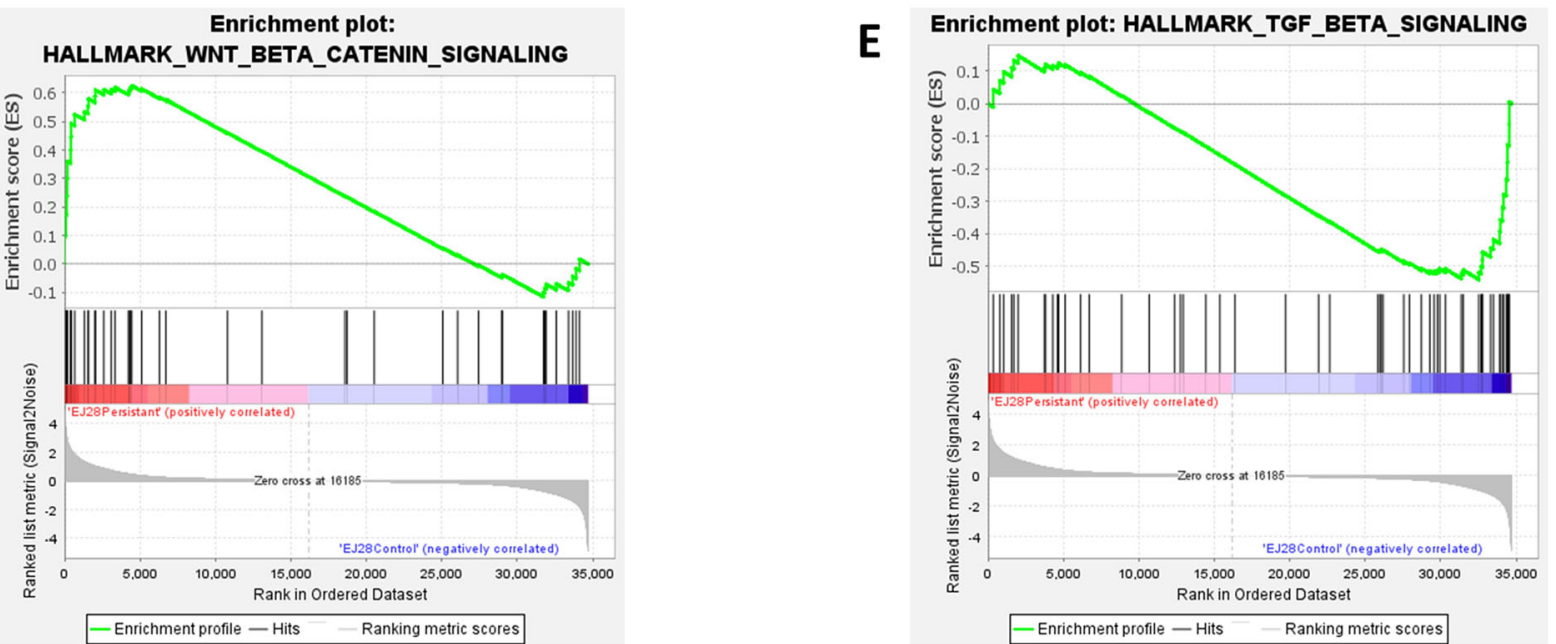

Fig. 4 GSEA reveals activation of cell proliferation and cell growth signalling pathways in EJ28P. GSEA was performed using the hallmark genes set from MSigDB with (A) upregulated genes and (B) downregulated genes. Enriched pathways with FDR $<0.25$ are shown in black while FDR $>$ 0.25 are shown in grey. GSEA enrichment plots for (C) Hallmark-Wnt/ $\beta$-catenin Signalling, (D) Hallmark-TGF- $\beta$ Signalling. (E) Heatmap of enriched genes in the Wnt/ $\beta$-catenin signalling pathway. (F) Heatmap of enriched genes in the TGF- $\beta$ signalling pathway 


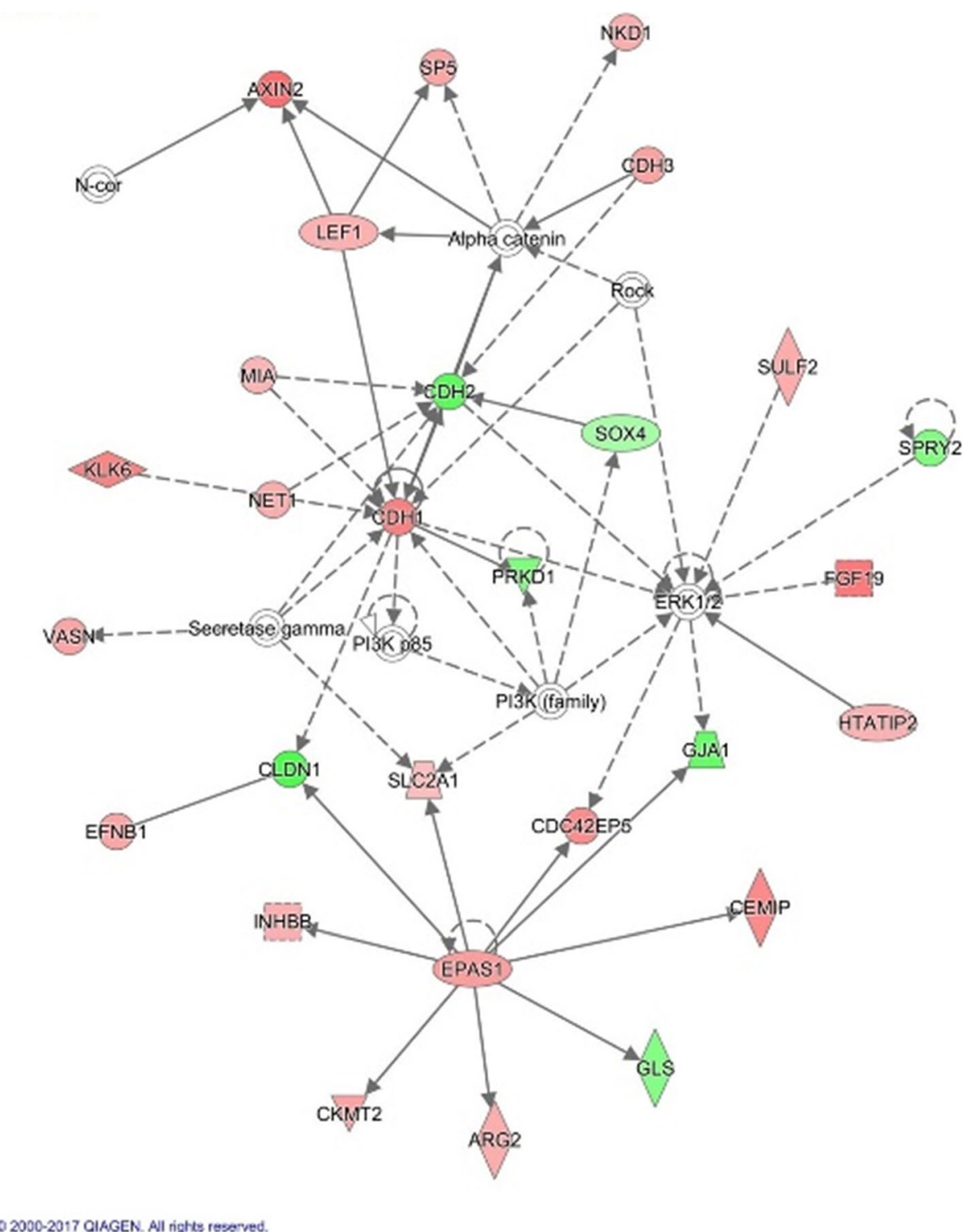

Fig. 5 Network of gene interactions identified by IPA. The network is displayed graphically as nodes (genes) and edges (the biological relationships between nodes). The network shows that EPAS1 is an important regulator gene that controls the expression of multiple genes. Most of the genes within the network are associated with the Wnt/ $\beta$-catenin signalling pathway. Nodes coloured in red indicates upregulated expression while nodes coloured in green indicates downregulated expression. (QIAGEN

Inc., https://www.qiagenbioinformatics.com/products/ingenuity-pathway-analysis)

[11] such as (i) resistance to NDV superinfection and (ii) continuously producing viral progenies. Nevertheless, a small population of early apoptotic cells were observed in mock-infected EJ28P cells as compared to the mockinfected EJ28 cells. Similar observation was also reported by Fox \& Parks (2018), who concluded that the persistently infected cells have higher basal levels of cellular stress that contributes to the relatively small percentage of cell death [14]. To pinpoint the possible underlying mechanism(s) associated with persistent NDV infection, we performed transcriptome analysis to identify significant genes and pathways that have been altered in NDV persistently infected EJ28P as compared to EJ28 cells.

GSEA was used to identify the hallmark gene sets that have been differentially regulated in EJ28P cells. Gene sets that were upregulated included $\mathrm{Wnt} / \beta$-catenin signalling, hedgehog signalling, oestrogen response early and late, and MYC target V1 and V2. All these gene sets are involved in the regulation of cell cycle, cell proliferation and cell growth. Interestingly, a previous study on the mechanism of NDV infection showed that NDV 
A

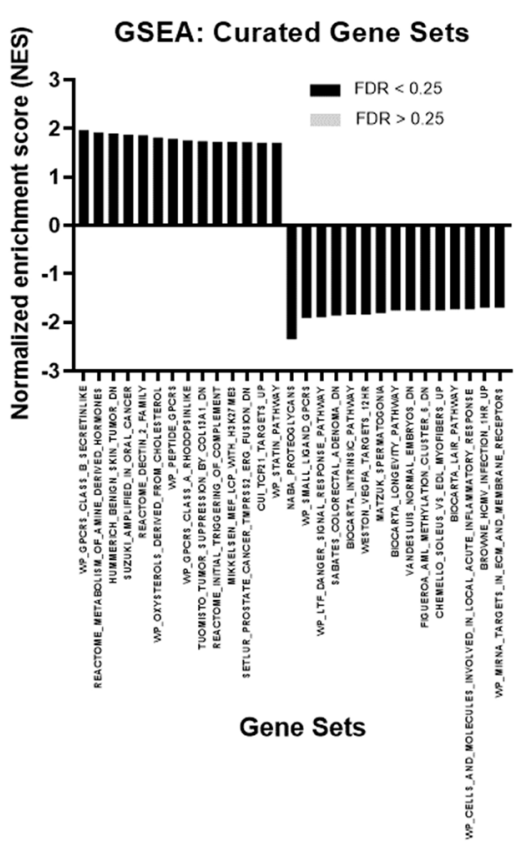

B

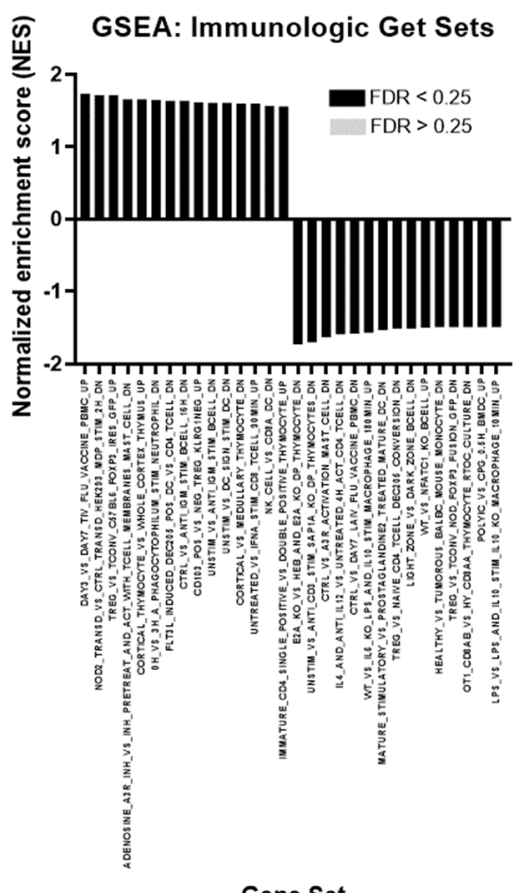

Gene Set

C

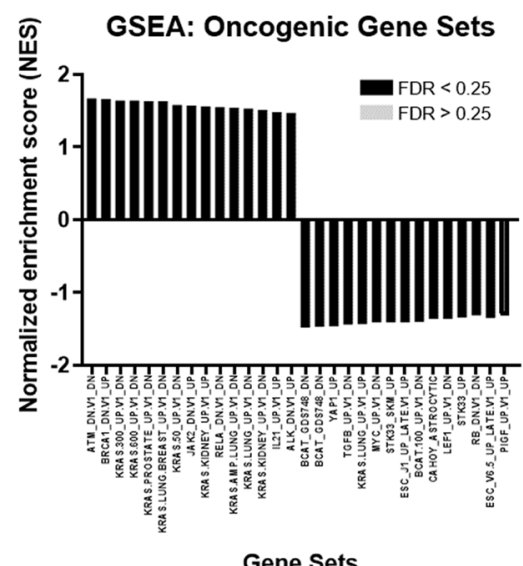

Fig. 6 Enrichment analysis by GSEA using different gene set collection. (A) GSEA using the Curated Gene Set collection. (B) GSEA using the Immunologic Gene Sets collection. (C) GSEA using the Oncogenic Gene Sets collection. All the significantly enriched pathways are presented in black $(F D R<0.25)$ or grey $(F D R<0.25)$

mediates oncolysis via the downregulation of $\mathrm{Wnt} / \beta$-catenin signalling pathway to promote apoptosis and inhibit cell migration [38]. This pathway could be dysregulated by viral-host interaction in order to establish and maintain viral latency in host cells [39]. Hence, we hypothesised that $\mathrm{Wnt} / \beta$-catenin signalling pathway could be involved in the persistent infection of NDV in EJ28 cells.

NDV is well known for its ability to induce both extrinsic and intrinsic apoptotic signalling in cancer cells [9]. However, the ability of EJ28P to survive NDV-mediated oncolysis suggests that the antiapoptosis or pro-survival signalling could be upregulated. The transcriptome analysis revealed several genes, which are associated with the regulation of cell survival such as S100A4 and SYK, both of which were upregulated in EJ28P. Incidentally, S100A4 expression is positively regulated by the Wnt/ß-catenin signalling pathway [40] to protect cells from pro-apoptotic stimuli $[41,42]$. It was reported that the knockdown of S100A4 decreased cellular proliferation and promoted apoptosis [42]. Meanwhile, the $S Y K$ gene was reported to provide pro-survival signals [43] whereas the inhibition of its protein expression resulted in apoptosis and the suppression of cellular proliferation [44]. 


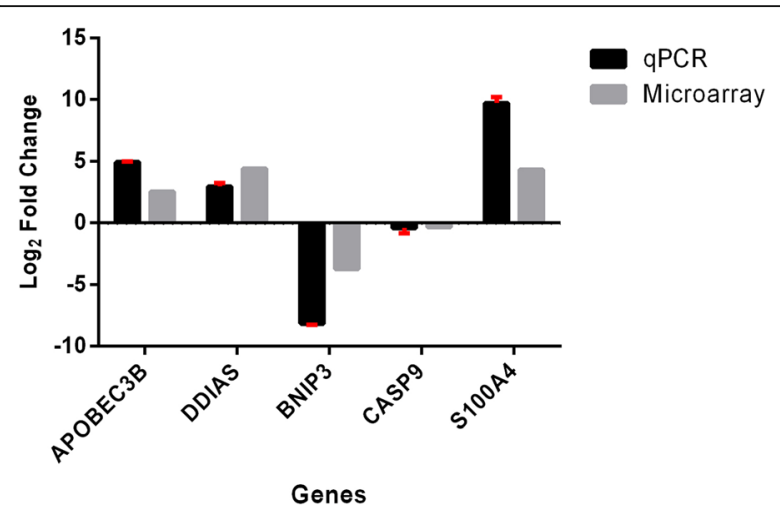

Fig. 7 Validation of microarray data by RT-qPCR analysis. The relative expression of the selected DEGs quantified by RT-qPCR and microarray are presented as log2 fold change. The expression pattern was similar. Both techniques found that three DEGs (APOBEC3B, DDIAS, and S100A4) were upregulated while two DEGs were downregulated (BNIP3 and CASP9). All data were presented as mean \pm standard deviation $(n=3)$

TGF- $\beta$ signalling pathway have been shown to be upregulated by many viruses, such as hepatitis $B$ virus, Influenza A virus and lymphocytic choriomeningitis virus, during infection [45-48]. Nevertheless, GSEA analysis showed that this pathway was downregulated in EJ28P cells. The downregulation of this pathway is hypothesised to hamper successful viral replication in the host cells. However, our study showed that the EJ28P cells were persistently infected by NDV and the cells continued to produce viral progenies. This suggests that TGF$\beta$ signalling pathway may not play an important role in the persistent infection of NDV in EJ28P. Bottler et al. (2012) also showed that TGF- $\beta$ blockade failed to control the establishment of persistent virus infection [45].

GSEA also revealed that DEGs associated with KRAS signalling were enriched in EJ28P cells. Activation of the proto-oncogene KRAS mutation pathway is common in cancer cells and it is responsible for promoting apoptosis inhibition, migration and proliferation in many cancer cells [49-51]. In addition, KRAS signalling enhances the $\mathrm{Wnt} / \beta$-catenin signalling resulting in tumour multiplicity and progression [52]. A close-up analysis on these DEGs showed that several negative regulators of apoptosis were upregulated in EJ28P cells, including TNFR SF1B, TMEM158, and FGF9. Several studies reported that TNFRSF1B could induce pro-survival pathways and protect cells from TNF-induced apoptosis [33, 34, 53, 54]. On the other hand, in vitro siRNA knockdown of TMEM158 have resulted in the inhibition of cell proliferation and increased apoptosis in cancer cells [35, 36]. Increased levels of FGF9 expression via transient transfection has shown to decrease cisplatin-induced cellular apoptosis while siRNA knockdown of FGF9 increased cisplatin-induced cellular apoptosis [55].
It was also revealed that cell proliferation and cell growth associated genes such as CCND2 and CL13ORF15 (RGCC) were upregulated in EJ28P cells. CCND2 plays a critical role in cell cycle regulation where it was reported that overexpression of CCND2 in cancer cells is associated with enhanced cell proliferation and aggressiveness [56]. In addition, CL13ORF15 (RGCC) was found to modulate the cell cycle and induce mitosis [57]. The upregulation of glucose transporter protein genes such as SLC2A3 and TEMEM16A (ANO1) also suggest that the cells require large amounts of energy in order to sustain cellular metabolism that is required for cellular proliferation and growth due to the upregulation of the $\mathrm{Wnt} / \beta$-catenin signalling pathway. In a nutshell, the transcriptome analysis and GSEA collectively support the postulate that $\mathrm{Wnt} / \beta$-catenin signalling pathway is involved in persistent infection of NDV in bladder cancer cells via the modulation of cellular survival, proliferation, and anti-apoptosis.

\section{Conclusions}

This study established persistent infection of NDV in bladder cancer cells and identified putative genes and pathways that are associated with persistent infection. It provides a snapshot of the cohesive transcriptomic dysregulation that occurs during persistent infection of NDV in bladder cancer cells (i.e. EJ28P). The biological significance of the $\mathrm{Wnt} / \beta$-catenin signalling pathway in conferring and maintaining the persistent infection warrant further investigation.

\section{Abbreviations}

NDV: Newcastle disease virus; GSEA: Gene set enrichment analysis; RTqPCR: Quantitative reverse transcription reaction chain; KEGG: Kyoto Encyclopedia of Genes and Genomes; DEG: Differentially expressed gene; TGF- $\beta$ : Transforming growth factor beta; TNF: tumour necrosis factor; PBS: Phosphate-buffered saline; CRC: Colorectal cancer; GFP: Green fluorescent protein; MM: Maintenance medium; GM: Growth medium; DMEM: 's Modified Eagle Medium; FBS: Foetal bovine serum; $\mathrm{CO}_{2}$ : Carbon dioxide; EDTA: Acid; RIN: RNA integrity number; PFU: Plaque forming unit; hpi: Hour post infection; rAF-GFP: Recombinant AF2240 GFP gene;

IPA: Ingenuity Pathway Analysis; SYK: Spleen associated tyrosine kinase

\section{Supplementary Information}

The online version contains supplementary material available at https://doi. org/10.1186/s12885-021-08345-y.

Additional file 1: Figure S1: Comparison of virus titres between EJ28 and EJ28P; Figure S2: GFP expression of rAF-GFP-infected EJ28P; Figure S3: Parental EJ28 and EJ28P infected or mock-infected with NDV labelled with annexin $\mathrm{V}$ and $\mathrm{Pl}$;

Additional file 2: Table S1: Differently expressed genes with Padj < 110 and absolute LOG2 fold change of 2 in expression levels between EJ28P and EJ28

Additional file 3: Figure S4: Gene markers for the EJ28P versus EJ28 comparison; Table S2: Details of top 20 significant DEGs between EJ28P and EJ28; Table S3: Gene set of HALLMARK_KRAS_SIGNALING_UP enriched in EJ28P 


\section{Acknowledgements}

Not applicable.

\section{Authors' contributions}

Conceptualization: MJM, AV, KY, S-CC and S-LC; Formal analysis: L-CC., JK., SWL and S-CC; Funding acquisition: S-CC and S-LC; Investigation: L-CC; Project administration: S-CC and S-LC; Resources: AV, KY, S-CC and S-LC; Supervision: KY, S-CC and S-LC; Visualization: L-CC and JK; Original draft: L-CC and JK; Review and editing: S-WL, MJM, AV, KY, S-CC and S-LC. All Authors have read and approved the manuscript.

\section{Funding}

This work was supported by the Ministry of Energy, Science, Technology, Environmental and Climate Change, Malaysia under the DSTIN Flagship Programme research grant no. FP0514B0021-2 (DSTIN), Ministry of Higher Education, Malaysia, Fundamental Research Grant Scheme (FRGS) grant no. FRGS/2/2014/SKK01/PERDANA/03/1, and Universiti Putra Malaysia internal grants no. GT-IPM/2013/9404400 and GT-IPS/2013/9397000. The funding agencies did not have any role in design of the study, data collection, analysis, interpretation of the results and writing of the manuscript.

\section{Availability of data and materials}

The datasets used and/or analysed during the current study are available from the corresponding author on reasonable request.

\section{Declarations}

Ethics approval and consent to participate

Not applicable.

\section{Consent for publication}

Not applicable.

\section{Competing interests}

The authors declare that they have no competing interests.

\section{Author details}

${ }^{1}$ Department of Microbiology, Faculty of Biotechnology and Biomolecula Sciences, Universiti Putra Malaysia, UPM, 43400 Serdang, Selangor Darul Ehsan, Malaysia. ${ }^{2}$ Malaysia Genome Institute, Ministry of Science, Technology and Innovation, Jalan Bangi, 43000 Kajang, Selangor Darul Ehsan, Malaysia. ${ }^{3}$ Department of Cell and Molecular Biology, Faculty of Biotechnology and Biomolecular Sciences, Universiti Putra Malaysia, 43400 UPM Serdang, Selangor Darul Ehsan, Malaysia. ${ }^{4} U P M-M A K N A$ Cancer Research Laboratory, Institute of Bioscience, Universiti Putra Malaysia, 43400 UPM Serdang, Selangor Darul Ehsan, Malaysia. ${ }^{5}$ Department of Biological Sciences, School of Medical and Life Sciences, Sunway University, 47500 Bandar Sunway, Selangor Darul Ehsan, Malaysia. ${ }^{6}$ Medical Genetics Laboratory, Faculty of Medicine and Health Sciences, Universiti Putra Malaysia, 43400 UPM Serdang, Selangor Darul Ehsan, Malaysia. ${ }^{7}$ Perdana University School of Liberal Arts, Science and Technology (PUSCLST), Perdana University, 50490 Kuala Lumpur, Malaysia.

\section{Received: 22 May 2020 Accepted: 12 May 202}

Published online: 27 May 2021

\section{References}

1. Kim S, Wanasen N, Paldurai A, Xiao S, Collins PL, Samal SK. Newcastle disease virus fusion protein is the major contributor to protective immunity of genotype-matched vaccine. PloS One. 2013;8(8):e74022.

2. Song KY, Wong J, Gonzalez L, Sheng G, Zamarin D, Fong Y. Antitumor efficacy of viral therapy using genetically engineered Newcastle disease virus [NDV(F3aa)-GFP] for peritoneally disseminated gastric cancer. J Mol Med. 2010;88(6):589-96. https://doi.org/10.1007/s00109-010-0605-6.

3. Schirrmacher $V$. Fifty years of clinical application of Newcastle disease virus: time to celebrate! Biomedicines. 2016:4(3):e16.

4. Kalyanasundram J, Hamid A, Yusoff K, Chia SL. Newcastle disease virus strain \{AF2240\} as an oncolytic virus: a review. Acta Trop. 2018;183:126-33. https:// doi.org/10.1016/j.actatropica.2018.04.007.

5. Yurchenko KS, Zhou P, Kovner AV, Zavjalov EL, Shestopalova LV, Shestopalov AM. Oncolytic effect of wild-type Newcastle disease virus isolates in cancer cell lines in vitro and in vivo on xenograft model. PLoS One. 2018:3(4):e0195425.

6. Reichard KW, Lorence RM, Cascino CJ, Peeples ME, Walter RJ, Fernando MB, et al. Newcastle disease virus selectively kills human tumor cells. J Surg Res. 1992;53(5):448-53.

7. Stojdl DF, Lichty B, Knowles S, Marius R, Atkins H, Sonenberg N, et al. Exploiting tumor-specific defects in the interferon pathway with a previously unknown oncolytic virus. Nat Med. 2000;6(7):821-5. https://doi. org/10.1038/77558.

8. Fiola C, Peeters B, Fournier P, Arnold A, Bucur M, Schirrmacher V. Tumor selective replication of Newcastle disease virus: association with defects of tumor cells in antiviral defence. Int J Cancer. 2006;119(2):328-38. https://doi. org/10.1002/ijc.21821.

9. Elankumaran S, Rockemann D, Samal SK. Newcastle disease virus exerts oncolysis by both intrinsic and extrinsic caspase-dependent pathways of cell death. J Virol. 2006;80(15):7522-34. https://doi.org/10.1128/JVI.00241-06.

10. Biswas M, Kumar SR, Allen A, Yong W, Nimmanapalli R, Samal SK, et al. Celltype-specific innate immune response to oncolytic Newcastle disease virus. Viral Immunol. 2012;25(4):268-76. https://doi.org/10.1089/vim.2012.0020.

11. Chia SL, Yusoff K, Shafee N. Viral persistence in colorectal cancer cells infected by Newcastle disease virus. Virol J 2014;11(1):1-8, 91, doi: https:// doi.org/10.1186/1743-422X-11-91.

12. Rangaswamy US, Wang W, Cheng X, McTamney $P$, Carroll D, Jin $\mathrm{H}$. Newcastle disease virus establishes persistent infection in tumor cells in vitro: contribution of the cleavage site of fusion protein and second sialic acid binding site of hemagglutinin-neuraminidase. J Virol. 2017;91(16): e00770-17.

13. Chia SL, Tan WS, Yusoff K, Shafee N. Plaque formation by a velogenic Newcastle disease virus in human colorectal cancer cell lines. Acta Virol. 2012;56(4):345-7. https://doi.org/10.4149/av_201204 345.

14. Fox CR, Parks GD. Parainfluenza virus infection sensitizes cancer cells to DNA-damaging agents: implications for oncolytic virus therapy. J Virol. 2018; 92(7):e01948-17.

15. Fei F, Qu J, Li C, Wang X, Li Y, Zhang S. Role of metastasis-induced protein S100A4 in human non-tumor pathophysiologies. Cell Biosci. 2017;7(1):1-10.

16. Hou S, Tian T, Qi D, Sun K, Yuan Q, Wang Z, et al. S100A4 promotes lung tumor development through $\beta$-catenin pathway-mediated autophagy inhibition. Cell Death Dis. 2018:9(3):1-15.

17. Song C, Ren J, Ran L, Li Y, Li X, Chen X, et al. Cyclin D2 plays a regulatory role in HBV replication. Virology. 2014:462:149-57.

18. Schlick SN, Wood CD, Gunnell A, Webb HM, Khasnis S, Schepers A, et al. Upregulation of the cell-cycle regulator RGC-32 in Epstein-Barr virusimmortalized cells. PLoS One. 2011;6(12):e28638. https://doi.org/10.1371/ journal.pone.0028638.

19. Fosbrink M, Cudrici C, Niculescu F, Badea TC, David S, Shamsuddin A, et al. Overexpression of RGC-32 in colon cancer and other tumors. Exp Mol Pathol. 2005;78(2):116-22. https://doi.org/10.1016/j.yexmp.2004.11.001.

20. Luangdilok S, Box C, Patterson L, Harrington K, Pitkin L, Rhŷs-Evans P, et al. Syk tyrosine kinase is linked to cell motility and progression in squamous cell carcinomas of the head and neck. Cancer Res. 2007;67(16):7907-16. https://doi.org/10.1158/0008-5472.CAN-07-0331.

21. Yu Y, Rahmanto YS, Lee M, Wu P, Phillip JM, Huang C, et al. Inhibition of ovarian tumor cell invasiveness by targeting SYK in the tyrosine kinase signaling pathway. Oncogene. 2018;37(28):3778-89. https://doi.org/10.1038/ s41388-018-0241-0.

22. Starska K, Forma E, Jóźwiak P, Bryś M, Lewy-Trenda I, Brzezińska-Błaszczyk E, et al. Gene and protein expression of glucose transporter 1 and glucose transporter 3 in human laryngeal cancer-the relationship with regulatory hypoxia-inducible factor-1 a expression, tumor invasiveness, and patient prognosis. Tumor Biol. 2015;36(4):2309-21. https://doi.org/10.1007/s13277014-2838-4.

23. Kuo MH, Chang WW, Yeh BW, Chu YS, Lee YC, Lee HT. Glucose transporter 3 is essential for the survival of breast Cancer cells in the brain. Cells. 2019; 8(12):1568. https://doi.org/10.3390/cells8121568.

24. Yao X, He Z, Qin C, Deng X, Bai L, Li G, et al. SLC2A3 promotes macrophage infiltration by glycolysis reprogramming in gastric cancer. Cancer Cell Int. 2020;20(1):1-16

25. Crutzen R, Virreira M, Markadieu N, Shlyonsky V, Sener A, Malaisse WJ, et al. Anoctamin 1 (Ano1) is required for glucose-induced membrane potential oscillations and insulin secretion by murine $\beta$-cells. Eur J Physiol. 2016; 468(4):573-91. https://doi.org/10.1007/s00424-015-1758-5. 
26. Kunzelmann K, Ousingsawat J, Benedetto R, Cabrita I, Schreiber R. Contribution of anoctamins to cell survival and cell death. Cancers. 2019; 11(3):382. https://doi.org/10.3390/cancers11030382.

27. Hedge TA, Mason I. Expression of Shisa2, a modulator of both Wnt and Fgf signaling, in the chick embryo. Int J Dev Biol. 2003;52(1):81-5.

28. Nagano T, Takehara S, Takahashi M, Aizawa S, Yamamoto A. Shisa2 promotes the maturation of somitic precursors and transition to the segmental fate in Xenopus embryos. Development. 2006;133(23):4643-54. https://doi.org/10.1242/dev.02657.

29. Hedge TA, Mason I. Expression of Shisa2, a modulator of both Wnt and Fgf signaling, in the chick embryo. Int J Dev Biol. 2008;52(1):81-5. https://doi. org/10.1387/ijdb.072355th.

30. Metkar SS, Wang B, Aguilar-Santelises M, Raja SM, Uhlin-Hansen L, Podack E, et al. Cytotoxic cell granule-mediated apoptosis: perforin delivers granzyme B-serglycin complexes into target cells without plasma membrane pore formation. Immunity. 2002;16(3):417-28. https://doi.org/10.1016/S1074-7613 (02)00286-8

31. Raja SM, Wang B, Dantuluri M, Desai UR, Demeler B, Spiegel K, et al. Cytotoxic cell granule-mediated apoptosis: characterization of the macromolecular complex of granzyme B with serglycin. J Biol Chem. 2002; 277(51):49523-30. https://doi.org/10.1074/jbc.M209607200.

32. Melo FR, Waern I, Rönnberg E, Åbrink M, Lee DM, Schlenner SM, et al. A role for serglycin proteoglycan in mast cell apoptosis induced by a secretory granule-mediated pathway. J Biol Chem. 2011;286(7):5423-33. https://doi. org/10.1074/jbc.M110.176461.

33. Rothe M, Pan MG, Henzel WJ, Ayres TM, Goeddel DV. The TNFR2-TRAF signaling complex contains two novel proteins related to baculoviral inhibitor of apoptosis proteins. Cell. 1995;83(7):1243-52. https://doi.org/10.1 016/0092-8674(95)90149-3.

34. Espin R, Roca FJ, Candel S, Sepulcre MP, Gonzalez-Rosa JM, Alcaraz-Perez F, et al. TNF receptors regulate vascular homeostasis in zebrafish through a caspase-8, caspase-2 and P53 apoptotic program that bypasses caspase-3. Dis Models Mechanisms. 2013;6(2):383-96. https://doi.org/10.1242/dmm.01 0249 .

35. Liu L, Zhang J, Li S, Yin L, Tai J. Silencing of TMEM158 inhibits tumorigenesis and multidrug resistance in colorectal Cancer. Nutr Cancer. 2020;72(4):66271. https://doi.org/10.1080/01635581.2019.1650192.

36. Cheng Z, Guo J, Chen L, Luo N, Yang W, Qu X. Overexpression of TMEM158 contributes to ovarian carcinogenesis. J Exp Clin Cancer Res. 2015;34(1):1-9.

37. Ren C, Chen H, Han C, Fu D, Wang F, Wang D, et al. The anti-apoptotic and prognostic value of fibroblast growth factor 9 in gastric cancer. Oncotarget. 2016;7(24):36655. https://doi.org/10.18632/oncotarget.9131.

38. Morla S, Kumar A, Kumar S. Newcastle disease virus mediated apoptosis and migration inhibition of human oral cancer cells: a probable role of $\beta$-catenin and matrix metalloproteinase-7. Sci Rep. 2019;9(1):1-9.

39. van Zuylen WJ, Rawlinson WD, Ford CE. The Wnt pathway: a key network in cell signalling dysregulated by viruses. Rev Med Virol. 2016;26(5):340-55. https://doi.org/10.1002/rmv.1892.

40. Stein U, Arlt F, Walther W, Smith J, Waldman T, Harris ED, et al. The metastasis-associated gene S100A4 is a novel target of $\beta$-catenin/T-cell factor signaling in colon cancer. Gastroenterology. 2006;131(5):1486-500. https://doi.org/10.1053/j.gastro.2006.08.041.

41. Ma L, Chen Y, Han R, Wang S. Benzyl isothiocyanate inhibits invasion and induces apoptosis via reducing S100A4 expression and increases PUMA expression in oral squamous cell carcinoma cells. Braz J Med Biol Res. 2019; 52(4):e8409.

42. Liu J, Fu S, Xu Y, Zheng Z. RNA interference targeting inhibition of S100A4 suppresses cell growth and promotes apoptosis in human laryngeal carcinoma Hep-2 cells. fvMol Med Rep. 2014;10(3):1389-94. https://doi.org/1 $0.3892 / \mathrm{mmr} .2014 .2345$

43. Krisenko MO, Geahlen RL. Calling in SYK: SYK's dual role as a tumor promoter and tumor suppressor in cancer. Biochimica et Biophysica Acta Mol Cell Res. 2015;1853(1):254-63. https://doi.org/10.1016/j.bbamcr.2014.10. 022 .

44. Wilcox RA, Sun DX, Novak A, Dogan A, Ansell SM, Feldman AL. Inhibition of Syk protein tyrosine kinase induces apoptosis and blocks proliferation in Tcell non-Hodgkin lymphoma cell lines. Leukimia. 2010;24(1):229-32. https:// doi.org/10.1038/leu.2009.198.

45. Boettler T, Cheng Y, Ehrhardt K, von Herrath M. TGF- $\beta$ blockade does not improve control of an established persistent viral infection. Viral Immunol. 2012;25(3):232-8. https://doi.org/10.1089/vim.2011.0079.
46. Schwaiger T, Knittler MR, Grund C, Roemer-Oberdoerfer A, Kapp JF, Lerch MM, et al. Newcastle disease virus mediates pancreatic tumor rejection via NK cell activation and prevents cancer relapse by prompting adaptive immunity. Int J Cancer. 2017;141(12):2505-16. https://doi.org/10.1002/ijc.31 026.

47. Denney L, Branchett W, Gregory LG, Oliver RA, Lloyd CM. Epithelial-derived TGF- $\beta 1$ acts as a pro-viral factor in the lung during influenza a infection. Mucosal Immunol. 2018;11(2):523-35. https://doi.org/10.1038/mi.2017.77.

48. Li H, Zhai N, Wang Z, Song H, Yang Y, Cui A, et al. Regulatory NK cells mediated between immunosuppressive monocytes and dysfunctional T cells in chronic HBV infection. Gut. 2018;67(11):2035-44. https://doi.org/1 0.1136/gutjnl-2017-314098.

49. Buday L, Downward J. Many faces of Ras activation. Biochimica et Biophysica Acta (BBA)-reviews on. Cancer. 2008;1786(2):178-87.

50. Ouerhani S, Bougatef K, Soltani I, Elgaaied AB, Abbes S, Menif S. The prevalence and prognostic significance of KRAS mutation in bladder cancer, chronic myeloid leukemia and colorectal cancer. Mol Biol Rep. 2013;40(6): 4109-14. https://doi.org/10.1007/s11033-013-2512-8.

51. Werner K, Lademann F, Thepkaysone ML, Jahnke B, Aust DE, Kahlert C, et al. Simultaneous gene silencing of KRAS and anti-apoptotic genes as a multitarget therapy. Oncotarget. 2016;7(4):3984-92. https://doi.org/10.18632/ oncotarget.6766.

52. Janssen KP, Alberici P, Fsihi H, Gaspar C, Breukel C, Franken P, et al. APC and oncogenic KRAS are synergistic in enhancing Wnt signaling in intestinal tumor formation and progression. Gastroenterology. 2006;131(4):1096-109. https://doi.org/10.1053/j.gastro.2006.08.011.

53. Horie T, Dobashi K, lizuka K, Yoshii A, Shimizu Y, Nakazawa T, et al. Interferon-gamma rescues TNF-alpha-induced apoptosis mediated by upregulation of TNFR2 on EoL-1 cells. Exp Hematol. 1999;27(3):512-9. https:// doi.org/10.1016/S0301-472X(98)00058-7.

54. Liu C, Sun Z, Xu Z, Liu T, Pan T, Li S. Down-regulation of microRNA-155 promotes selenium deficiency-induced apoptosis by tumor necrosis factor receptor superfamily member 1B in the broiler spleen. Oncotarget. 2017; 8(35):58513-25. https://doi.org/10.18632/oncotarget.17222.

55. Zhang Z, Zhang Y, Qin X, Wang Y, Fu J. FGF9 promotes cisplatin resistance in colorectal cancer via regulation of Wnt/ $\beta$-catenin signaling pathway. Exp Ther Med. 2020;19(3):1711-8. https://doi.org/10.3892/etm.2019.8399.

56. Liu SC, Bassi DE, Zhang SY, Holoran D, Conti CJ, Klein-Szanto AJ. Overexpression of cyclin D2 is associated with increased in vivo invasiveness of human squamous carcinoma cells. Mol Carcinogenesis. 2002;34(3):131-9. https://doi.org/10.1002/mc.10057.

57. Tegla CA, Cudrici CD, Nguyen V, Danoff J, Kruszewski AM, Boodhoo D, et al. RGC-32 is a novel regulator of the T-lymphocyte cell cycle. Exp Mol Pathol. 2015;98(3):328-37. https://doi.org/10.1016/j.yexmp.2015.03.011.

\section{Publisher's Note}

Springer Nature remains neutral with regard to jurisdictional claims in published maps and institutional affiliations.

Ready to submit your research? Choose BMC and benefit from:

- fast, convenient online submission

- thorough peer review by experienced researchers in your field

- rapid publication on acceptance

- support for research data, including large and complex data types

- gold Open Access which fosters wider collaboration and increased citations

- maximum visibility for your research: over $100 \mathrm{M}$ website views per year

At $\mathrm{BMC}$, research is always in progress.

Learn more biomedcentral.com/submission 